\title{
Laboreal
}

Volume $6 \mathrm{~N}^{\circ} 2$ | 2010

Varia

\section{Pão e veneno : reflexões para uma investigação sobre o 'ambientalismo do trabalho' em Itália, 1968-1998}

Pan y veneno : reflexiones para una investigación sobre el 'ambientalismo del trabajo' en Italia, 1968 - 1998

Pain et poison : quelques pistes pour une recherche sur "l'environnementalisme du travail "en Italie, 1968-1998

Bread and poison: reflections for a research on labour environmentalism in Italy, 1968-1998

\section{Stefania Barca}

\section{CpenEdition}

\section{Journals}

\section{Edição electrónica}

URL: http://journals.openedition.org/laboreal/8590

DOI: $10.4000 /$ laboreal. 8590

ISSN: 1646-5237

\section{Editora}

Universidade do Porto

Refêrencia eletrónica

Stefania Barca, « Pão e veneno : reflexões para uma investigação sobre o 'ambientalismo do trabalho' em Itália, 1968-1998 ", Laboreal [Online], Volume 6 N² | 2010, posto online no dia 01 dezembro 2010, consultado o 10 outubro 2019. URL : http://journals.openedition.org/laboreal/8590; DOI : 10.4000/ laboreal.8590

Este documento foi criado de forma automática no dia 10 outubro 2019.

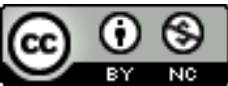

Laboreal está licenciado com uma Licença Creative Commons - Atribuição-NãoComercial 4.0 Internacional. 


\section{Pão e veneno : reflexões para uma investigação sobre o 'ambientalismo do trabalho’ em Itália, 1968-1998}

Pan y veneno : reflexiones para una investigación sobre el 'ambientalismo del trabajo' en Italia, 1968 - 1998

Pain et poison : quelques pistes pour une recherche sur "l'environnementalisme du travail " en Italie, 1968-1998

Bread and poison: reflections for a research on labour environmentalism in Italy, 1968-1998

\section{Stefania Barca}

\section{NOTA DO EDITOR}

Manuscrito recebido em : Setembro/2010

Aceite após peritagem : Novembro/2010

\section{Premissa}

1 A reflexão sobre o ambientalismo do trabalho em Itália apresenta-se inicialmente problemática : empreendidas desde o início dos anos ' 60 , as lutas sindicais que foram chamadas 'contra a nocividade' - isto é, para o controle dos trabalhadores sobre as condições ambientais na fábrica - acabaram para manter uma fraca e às vezes conflituosa relação com as batalhas ambientalistas, consideradas de elite (por exemplo, contra a especulação imobiliária, ou para o estabelecimento de áreas protegidas). $\mathrm{Na}$ memória de um dos protagonistas daquela fase, o médico do trabalho Massimo Menegozzo, a oportunidade de relacionar as lutas contra a nocividade na fábrica com a luta mais geral contra a poluição industrial, não foi aproveitada pelo movimento 
sindical [1]. Todavia, um simples exame da documentação disponível sobre o assunto, e da literatura historiográfica produzida até agora, deixa claro que considerar as lutas contra a nocividade apenas como parte da luta sindical italiana daqueles anos, ou do desenvolvimento da medicina do trabalho - ambas as questões centrais e bem analisadas até agora - seria uma subestima do valor cultural e político mais geral das mesmas lutas e do contributo que elas deram para o desenvolvimento do ambientalismo italiano.

2 A história contada neste artigo começa desde um encontro - entre uma geração de 'especialistas' em higiene industrial e uma outra de trabalhadores/as de fábrica - que teve lugar no coração do triângulo industrial italiano entre os anos ' 60 e ' 70 . Este encontro produziu novas formas de consciência ambiental e acção política, a que darei o nome de "ambientalismo do trabalho". Em seguida, a narração move-se para uma área de indústria petroquímica no Sul da Itália entre os anos '70 e ' 90 , onde as contradições da relação entre trabalho, saúde e meio ambiente explodiam e remontavam em diferentes formas. A minha intenção neste artigo é a de sugerir uma nova interpretação dessas lutas, inspirada por uma recente literatura históricoambiental sobre a nocividade industrial [²].

3 O ponto de partida teórico é a unidade orgânica e material entre trabalho, ambiente e saúde, como verificada pela "classe trabalhadora", isto é, o/as operário/as e suas famílias, através dos seus corpos e das condições materiais de trabalho e de vida [3]. 0 artigo também pretende realçar que esta unidade orgânica entre seres humanos e natureza através do trabalho tem sido tão ofuscada pelas forças políticas dominantes, como pelos contrastes entre o movimento operário e o ambientalista. A história do ambientalismo do trabalho italiano, entretanto, mostra a possibilidade de uma consciência antagonista do risco industrial, a qual surgiu em alguns momentos e lugares ao longo do último meio século. Mostra ainda como esse conhecimento tem sido capaz, de diferentes maneiras, de desafiar as formas estabelecidas do conhecimento científico, e até mesmo o poder político-económico.

4 Finalmente, este artigo visa contribuir para a construção de uma história do trabalho ambientalmente consciente. $\mathrm{O}$ meu argumento é de que os trabalhadores (e trabalhadoras) e as suas famílias não só trouxeram a marca do desenvolvimento capitalista em seus corpos, como foram eles os que pagaram o maior preço pela transformação ambiental tumultuosa do período pós-guerra. Assim, por estas razões, a história do trabalho contêm uma parte importante da história do ambiente na Itália. A formação de uma consciência ambiental do trabalho, com base na experiência do dano corporal, foi prejudicada pela grande mistificação cultural e política que afectou o crescimento económico italiano. Hoje é a responsabilidade da obra historiográfica o trazer à luz não somente os aspectos ambientais das lutas dos trabalhadores para a saúde, mas também a aç̧ão de forças opostas à formação duma frente unida entre consciência de classe e consciência ambiental.

O artigo resulta da reorganização de uma comunicação apresentada na conferência 'Dangerous Trade. Histories of industrial hazards across a globalizing world', realizada na Universidade de Stony Brook (EUA), em Dezembro de 2007. Sendo um levantamento preliminar das matérias e questões relacionadas com o tema do ambientalismo do trabalho italiano, o artigo utiliza uma variedade de fontes : (1) artigos da revista Sapere, durante o período da direcção de Giulio Maccacaro, (2) relatórios dos Serviços Médicos para os Ambientes de Trabalho da província de Milão (1972-1976) ; (3) entrevistas de 
história oral (realizadas pela autora), com dois dos protagonistas das lutas contra a nocividade; (4) entrevistas de história oral (publicadas) sobre o caso da indústria petroquímica em Manfredonia ; (8) literatura histórica sobre a nocividade industrial e sobre o contexto económico e político do período considerado.

\section{Os custos sociais do 'boom económico' (1958-1969)}

6 Entre 1955 e 1970, cerca de quatro milhões de Italianos migraram das áreas rurais e do Sul para o triângulo industrial, a maioria em busca de trabalho nas fábricas. Muitas encontraram-no nas áreas de rápido crescimento: aço, mecânica, e petroquímica. Desde o final dos anos 60, o Estado iniciou uma política de localização industrial no Sul do país, que transformou radicalmente as zonas costeiras, com a criação de grandes fábricas, a maioria de propriedade estatal, especialmente no sector petroquímico [ $\left.{ }^{4}\right]$.

7 Como resultado dessas mudanças, o país sofreu a transição epidemiológica típica das economias industrializadas, isto é, desde a prevalência de doenças infecciosas à prevalência de doenças degenerativas (cancro e doenças cardíacas), especialmente aquelas relacionadas com a contaminação ambiental por hidrocarbonetos, mercúrio e benzeno. O INAIL (Ente Italiano de Previdência Social) financiava a investigação no campo da higiene industrial, mas esta foi essencialmente direccionada para o seguro dos riscos e a patologia clínica, ao invés da prevenção. Prevaleceu um consenso tácito de que a saúde (e não apenas a dos trabalhadores) foi o preço a pagar pelo desenvolvimento industrial do país. Face à impressionante deterioração das condições de trabalho na fábrica, ligada à intensificação das taxas de produção, os sindicatos, por seu lado, adoptaram uma estratégia defensiva, focada em tentar obter o máximo possível de compensação por acidentes, e, em parte, por doenças do trabalho (muito difíceis de documentar e sempre sujeitas à recusa da autoridade de saúde). A compensação, ou - como viemos a dizer - a "monetarização" do risco industrial, não fazia mais do que impedir a prevenção, pelo simples fato de o INAIL cobrir os custos (e, em seguida, baixar grande parte deles no orçamento público), deixando os donos das empresas desprovidos de qualquer responsabilidade criminal e civil para os riscos do trabalho. $\mathrm{O}$ "milagre" da economia italiana foi, assim, em grande parte habilitado pelo baixo preço da saúde dos trabalhadores e das trabalhadoras e pela cobertura de seguro fornecida pelo Estado [5].

8 A experiência do ambientalismo do trabalho italiano começou quando uma geração de "especialistas" militantes - médicos, engenheiros e sociólogos do trabalho - começaram a entrar nas fábricas do milagre económico, ali chamados pelo mesmo movimento sindical na etapa crucial do "Outono quente", e encontraram o conhecimento dos riscos encarnado pelos trabalhadores e as trabalhadoras. Esse primeiro encontro havia sido preparado, por um lado, pelas reflexões sobre a relação entre saber e poder típica do movimento estudantil e, por outro, pela consciência do movimento operário (e da opinião pública) da existência de um enorme problema de saúde / segurança no trabalho causado pelo chamado "milagre económico". Essa consciência também produziu um amargo combate, após o que o novo Estatuto dos Trabalhadores foi aprovado pelo parlamento italiano (lei 300 de 1970). O Estatuto incluía dois artigos que expressamente reconheciam à classe trabalhadora o direito a exercer um controlo directo (isto é, não mediado pelos inspectores de trabalho ou "especialistas" na folha de 
pagamento do empregador) sobre as condições ambientais na fábrica. Experimentado durante os anos '60 em algumas realidades pioneiras, depois de 1970 este controlo sobre as condições de trabalho foi exercido amplamente e com sucesso, especialmente em grandes fábricas do triângulo industrial. Isto permitia a produção de uma significativa contribuição intelectual, da qual permanece marco nas páginas de revistas como "Medicina dei Lavoratori" e " Medicina Democrática", mas também numa revista não especializada como "Sapere" (particularmente durante o período em que foi dirigida por Giulio Maccacaro, que também dirigia nos mesmos anos a série "Medicina e Potere" da editora Feltrinelli), bem como uma extensa literatura especializada [ $\left.{ }^{6}\right]$.

9 Na reconstrução histórica, mas também nos testemunhos de pessoas que estiveram envolvidas, está claro como a experiência de luta pela saúde na fábrica foi utilizada para preparar o terreno para a reforma geral do sistema nacional de saúde pública, que efectivamente foi aprovada em 1978, após cinco greves gerais de "sangue e lágrimas" [7]. Eram anos em que a fábrica era considerada o foco da política e da vida social italiana, e em que a unidade orgânica entre saúde ocupacional e saúde pública era parte da maneira comum de perceber a realidade social e de saúde do país. A reforma de saúde nacional pareceu no entanto uma vitória da aliança entre a ciência militante e o conhecimento popular, entre especialistas/activistas e classe trabalhadora, o que resultou numa reforma muito mais ampla e geral, envolvendo todo o corpo social do país. Como veremos na segunda parte do artigo, o impacto dessas reformas institucionais sobre os órgãos dos trabalhadores e das trabalhadoras e sobre as condições ambientais de vida e trabalho no país, foi fortemente influenciado pelas hierarquias do contexto geográfico italiano e pelas mudanças políticas e económicas ao longo das décadas por vir.

\section{Ambiente de trabalho e medicina militante : a experiência dos SMAL}

10 A abordagem dos sindicatos à saúde ocupacional foi radicalmente revista nos anos " 60 após uma revolução em matéria de higiene industrial, que elaborava uma abordagem inovadora para a formação do conhecimento sobre condiçoes de saúde no ambiente de trabalho. Esta nova forma de conhecimento participativo baseava-se sobre uma radical revisão do papel dos "especialistas" de higiene industrial: desde cientistas supostamente imparciais, mas, de facto, ao serviço da empresa, para 'intelectuais orgânicos' ao serviço da classe trabalhadora. Rapidamente, a medicina ocupacional tornara-se numa ciência militante. Esta militança baseava-se em duas acções principais. A primeira consistia em formular de forma simples e clara alguns princípios básicos de higiene industrial, isso é: os quatro principais factores de risco: 1) factores inespecíficos (ruído, microclima, vibrações, radiações, etc.), 2) factores específicos do ambiente de trabalho (exposição a substâncias tóxicas ou explosivas), e 3) factores relacionados ao esforço físico (esforço, postura e movimentos incómodos) e 4) factores relacionados com a organização do trabalho (monotonia, ritmo excessivo, ansiedade, responsabilidade). A segunda acção da nova medicina ocupacional consistia na proposta do principio da não-delegação em matéria de saúde nos locais de trabalho, isso é, a ideia de que o impacto do trabalho sobre a saúde tinha que ser definido directamente pela classe trabalhadora, e não pelos "especialistas". Tudo isso levou a formular novos instrumentos de conhecimento administrados por trabalhadores e sindicatos: o 
questionário para colecta de dados, registos de dados ambientais e bioestatísticos, registos de dados sobre o estado de saúde dos trabalhadores [ ${ }^{8}$. Naquela época, o tema do "ambiente de trabalho" passou a ocupar um lugar de destaque no debate político interno da esquerda. Uma oficina permanente, rebaptizada "clube do ambiente", nasceu dentro da CGIL - o principal sindicato italiano - com a missão de formular e testar novas formas de conhecimento / acção contra a nocividade ["].

11 Uma experiência de grande importância, dentro deste fervor criativo em torno da questão dos riscos industriais, foi a do SMAL - Serviços de Medicina para os Ambientes de Trabalho : uma estrutura criada por iniciativa da CGIL-CISL-UIL (a federação dos três maiores sindicatos nacionais), e instituída pelo Governo Regional da Lombardia no final de 1972, com a tarefa de tornar imediatamente operacional o direito de controlo do ambiente da fábrica pelos trabalhadores. A experiencia do SMAL foi fortemente marcada pelo contexto regional, bem como pelo contexto histórico : ele foi criado no coração da área industrial (na província de Milão) e na época áurea da luta pela saúde na fábrica (1972 -1976). Seu valor é o de uma experiência pioneira, que teve a tarefa histórica de mostrar como foi possível configurar a questão do ambiente de trabalho, e com que resultados.

12 O SMAL realizara a sua tarefa de uma maneira activamente participada pelos trabalhadores e trabalhadoras, que passaram de "objecto" de investigação a atores: pois era o 'conselho de fábrica' que solicitava a intervenção dos "especialistas", e todas as acções a serem tomadas no âmbito do inquérito eram decididas por uma comissão pela "saúde e segurança" criada pelo mesmo conselho. A intervenção do SMAL baseavase essencialmente em ferramentas para o estudo auto-dirigido pelos trabalhadores, o que permitia a cada trabalhador e trabalhadora registar medições relacionadas com os quatro grupos de factores de risco, bem como com a sua própria condição psico-física e quaisquer males percebidos. A partir dos dados ambientais registados pelos trabalhadores, o SMAL tinha a opção de realizar um estudo nosológico e, eventualmente, exigir a gestão de medidas preventivas e / ou mudanças reais na estrutura organizacional e técnica da empresa.

13 Em suma, o SMAL tinha o poder de transformar a percepção dos trabalhadores e das trabalhadoras sobre riscos, presentes no local de trabalho em sérias mudanças na organização da produção, com a função de evitar o dano, ao invés de compensar o que já acontecera. Mobilizar o conhecimento do risco incorporado pela classe trabalhadora sobre os seus corpos, e que esta poderia finalmente usar em primeira pessoa para mudar as condições de trabalho na fábrica, foi a principal finalidade para a qual o SMAL nasceu. "A visão que um profissional pode construir sobre os perigos de um ambiente de trabalho - de acordo com um relatório SMAL - seria bastante insuficiente e parcial, se não fosse confrontada com a opinião de quem vive lá durante oito horas por dia '. Em resumo, o ambiente de trabalho era visto como um tipo específico de ecossistema, e a classe trabalhadora era a que o conhecia melhor $\left.{ }^{\left[{ }^{10}\right.}\right]$.

14 O SMAL não aparecia, assim, como um organismo científico fora do mundo do trabalho, extraindo conhecimento a partir do corpo dos trabalhadores, mas como um grupo de cientistas/activistas a serviço da classe trabalhadora sob a hegemonia incontestável dos sindicatos. Isto porque tinham sido precisamente os sindicatos a fazer pressão para o estabelecimento do SMAL a nível provincial e regional, depois de ter sido criado no seu orçamento por alguns governos locais. Foram os sindicatos a organizar cursos de formação para aspirantes médicos SMAL e a agir como intermediários entre eles e as 
organizações de trabalhadores; os sindicatos acabaram por coordenar os seus esforços a nível regional. A natureza militante do SMAL e, portanto, a prioridade política de defesa dos trabalhadores contra os riscos, é evidente nos relatórios da actividade realizada nos anos 1972-76 na província de Milão. A linguagem dos textos revela como os médicos [11] SMAL denotam ser muito mais do que apenas "especialistas" da saúde no acto da realização de um serviço público : eles são parte de uma batalha cultural mais geral contra o conhecimento / poder e para a subjectividade da classe trabalhadora, no acto de utilizar o ambiente de trabalho como um terreno importante da luta política e social. É frequentemente o caso de a sua acção abranger questões que ultrapassam o ambiente da fábrica, envolvendo a relação entre esta e o território, e portanto a questão politicamente muito delicada do conflito entre o trabalho e o meio ambiente.

Em Cinisello Bálsamo, por exemplo, uma disputa complexa foi levantada em relação ao ruído proveniente da fábrica de aço Terzago, colocando os trabalhadores em contraste com a população local. A direcção respondeu aos protestos da população, ordenando o fechamento das janelas, aumentando assim a carga de ruído em detrimento da saúde dos trabalhadores e trabalhadoras, e ameaçou fechar a fábrica em caso de reclamações por parte deles. A Terzago era uma pequena empresa com uma fraca presença dos sindicatos, onde a intervenção do SMAL havia sido chamada a pedido de um comité anti-ruído local. Portanto, é provável que os trabalhadores tenham reagido negativamente à intervenção do SMAL, percebendo-a como uma ameaça. Foi um caso politicamente sensível, o que exigiu a capacidade de superar a aparente contradição entre a saúde dos trabalhadores e a cidadania, bem como a capacidade de ligar os dois momentos da luta contra a poluição. O SMAL definiu o problema do ruído como um problema de saúde ocupacional em primeiro lugar, e agiu para abordar ambos pela raiz. Essa linha de acção necessitou de uma forma de intervenção não estritamente profissional. Um primeiro nível de acção foi reunir os trabalhadores e trabalhadoras com a população local por meio de assembleias de bairro, incluindo a participação de especialistas de otorrinolaringologia da Universidade de Milão e representantes do governo local. Só mais tarde, portanto, o SMAL passou a intervir nas condições de trabalho com o levantamento audiométrico. Os resultados evidenciaram surdez parcial crónica em $30 \%$ dos trabalhadores examinados e choque acústico noutros $36 \%$, na sua maioria mulheres. Porém, a intervenção do SMAL não se limitando à verificação dos danos à saúde dos trabalhadores, começou a procurar uma solução técnica. Mediante a cooperação de "engenheiros democráticos" - informa o relatório - foram apresentadas propostas concretas para o controlo de vibrações e transmissão de ondas acústicas no local de trabalho. No final, a direcção não só não pôs em causa os resultados da pesquisa, como se mostrou disposta a adoptar todas as soluções propostas $\left.{ }^{[12}\right]$.

16 A conexão entre conflitos ambientais e da área da fábrica é também evidente noutro relatório, sobre a Metal-Lámina em Assago. Neste caso, foi o conselho de trabalhadores de uma empresa próxima a chamar a atenção do serviço municipal de ecologia para as emissões da Metal-Lámina. Este, por sua vez, procurou a intervenção do SMAL. A pesquisa evidenciou que o ambiente de trabalho foi contaminado com pó de chumbo em quantidades dez vezes superiores ao permitido. Os trabalhadores relataram que cinco cães de guarda já estavam mortos dentro da fábrica no ano passado, provavelmente devido à ingestão de poeira depositada sobre o solo. O SMAL deu instruções para a admissão hospitalar imediata de oito dos treze fundadores, e ordenou a paragem da produção em todo o bloco de Fundição. A administração da empresa ameaçou fechar a fábrica. No final, porém, não só decidiu aplicar todas as disposições 
para a redução de fumos e poeiras ditada pelo SMAL e pelo serviço municipal de Ecologia, incluindo a instalação de um purificador de água, como ainda sugeriu que o SMAL se tornasse consultor da empresa em questões de saúde e meio ambiente [13].

O comportamento da direcção da Metal-Lámina parece ter sido bastante comum noutras pequenas e médias empresas tocadas pela intervenção do SMAL. O único caso em que este encontrou resistência e até oposição aberta foram as empresas do grupo Montedison, onde a gestão prejudicou por todos os meios a admissão de especialistas SMAL, alegando ter seu próprio serviço médico [ $\left.{ }^{14}\right]$. Este facto introduz o tema da secção seguinte, respeitante às lutas contra a nocividade na grande empresa estatal petroquímica.

\section{Manfredonia 1976-1998 : Ambiente e Trabalho num Pólo Petroquímico do Sul}

18 Na manhã de 26 Setembro de 1976, apenas dois meses após o acidente em Seveso, a explosão de uma coluna de arsénio na fábrica ANIC de Manfredonia, na província de Foggia, causou a descarga na atmosfera de uma nuvem de 32 toneladas de dióxido de arsénio em pó, que caiu sobre a cidade e se depositou em terrenos agrícolas circundantes $\left[15^{15}\right]$. Os primeiros sintomas de um envenenamento em massa eram evidentes logo após a morte de muitos animais, e a hospitalização de cerca de uma centena de pessoas em poucas horas. Os pacientes foram quase todos trabalhadores da fábrica e moradores do bairro Monticchio, um aglomerado de habitações sociais construídas perto da fábrica ANIC. Incrivelmente, a gestão da fábrica negou a existência de qualquer risco epidemiológico, e chamou todos os trabalhadores para trabalhar normalmente na segunda-feira seguinte. Como uma medida preventiva, uma equipa de pessoal de manutenção foi enviada no mesmo dia para limpar o interior do estabelecimento, sem qualquer protecção e munidos apenas com vassouras. Esses trabalhadores estiveram toda a noite a recolher o pó de arsénio depositado, de modo que a planta pudesse voltar a funcionar 'normalmente' no dia seguinte.

O acidente aconteceu em uma área do Sul que sofreu com elevada taxa de desemprego crónico e emigração, uma área cujos recursos mais importantes haviam sido a terra agrícola, utilizada sobretudo com oliveiras, a pesca e a paisagem natural/histórico (Manfredonia é a entrada para a península de Gargano). Esses recursos tinham vindo a ser seriamente comprometidos não só pelo acidente de 1976, mas por mais de 20 anos de actividade do estabelecimento ANIC (que em seguida irá chamar-se Enichem). Em 1988, a Organização Mundial de Saúde classificou a área como de "alto risco de crise ecológica" por causa da contaminação da cadeia alimentar, e sugeriu a criação de um observatório epidemiológico permanente [16]. Contudo, a população continuou a ignorar as ameaças relacionadas com a longa actividade da indústria petroquímica no seu território, e os efeitos da propagação da contaminação por arsénico que este sofreu em 1976. A prioridade política (e, claro, da empresa) foi, de imediato, a de evitar a disseminação de informações para prevenir a formação de uma situação tipo Seveso, onde se verificou a mobilização de comités de cidadãos, partidos políticos, organizações sociais, o bloco da fábrica, evacuações, assistência de peritos estrangeiros e alerta da opinião pública internacional. Nada disto aconteceu realmente em Manfredonia, exceptuando o surgimento de algumas vozes, como a do Democrazia Proletaria, o único partido a organizar um evento anti-ANIC importante, em que os trabalhadores, 
pescadores e moradores do bairro Monticchio denunciaram os ataques ao meio ambiente e à saúde pública cometidos pela empresa com o consentimento tácito das autoridades locais [17].

Em Manfredonia não houve a intervenção de qualquer SMAL, nem naquela nem noutras ocasiões durante mais de 20 anos de operação da fábrica Enichem. 0 único médico sério que foi visto na companhia, lembra um dos trabalhadores entrevistados por Giulio di Luzio (2003) para o livro-reportagem Os Fantasmas da Enichem, foi mandado embora em redor de dois meses. Pelo contrário, o incidente de 1976 revelou a existência de um padrão bem estabelecido de relações entre medicina e poder político, com a tarefa de salvaguardar os interesses da indústria petroquímica, em detrimento dos trabalhadores e da população de Manfredonia. A emissão de dados laboratoriais extremamente tardia e a manipulação deliberada de informações sobre os níveis de contaminação permitidos (MAC) foram as ferramentas através das quais os médicos das Clínicas do Trabalho de Bari e Milão, alguns dos quais já consultores ANIC, colaboraram com as autoridades e com a empresa para manter em segredo os efeitos reais do acidente.

21 A falta de iniciativa dos sindicatos (principalmente comandado por homens), teve o efeito inesperado de activar uma outra agência histórica, a eco-feminista [18]. Foi realmente um grupo de 40 mulheres, em grande parte moradoras do bairro Monticchio, que se uniu na organização Bianca Lancia - Movimento Cidadão de Mulheres, na mobilização para o reconhecimento do dano. O movimento ganhou um importante avanço em 1978, quando o Tribunal de Justiça Europeu concordou em avaliar o caso, embora o veredicto final, obtido após dez anos, se tenha mostrado muito abaixo das expectativas. As mulheres de Manfredonia ganharam reconhecimento apenas pelos danos materiais, ou seja, a violação do seu "direito de conhecer" os riscos potenciais decorrentes do estabelecimento. Mas não conseguiram o que esperavam, ou seja, o reconhecimento dos danos biológicos: a contaminação do ar, água, solo e corpos humanos e, portanto, de todo o ambiente de Manfredonia. Em resumo, a empresa foi condenada por esconder informações sobre o risco, mas não pela sua responsabilidade directa por ter causado o dano.

Nos 20 anos seguintes ao acidente de 1976, a relação entre a classe trabalhadora e a cidade de Manfredonia irá revelar-se complexa e cheia de contradições, às vezes explodindo em conflitos abertos. Ainda assim algo significativo tinha que acontecer em Manfredonia, abrindo uma nova oportunidade histórica para o ambientalismo da classe trabalhadora, e mais uma vez foi um encontro : entre o trabalhador aposentado Nicola Lovecchio e o médico radiologista Maurizio Portaluri, que teve lugar no hospital de San Giovanni Rotondo em 1994 [ $\left.{ }^{19}\right]$. Neste ponto, a história de Manfredonia reúne-se com a dos trabalhadores do grupo Enichem noutra área, a de Porto Marghera. Antes do encontro com Lovecchio, de facto, Portaluri tinha lido o dossier elaborado pelo extrabalhador de Marghera Gabriele Bortolozzo e publicado pelo jornal Medicina Democratica em 1994 [ $\left.{ }^{20}\right]$. Portaluri propôs a Lovecchio, ex-gerente do departamento de embalagem de fertilizantes no estabelecimento Enichem, que começasse a recolher informações sobre a sua doença, bem como sobre as de muitos colegas, e sobre as condições ambientais na fábrica. Lovecchio aceitou (e continuou no compromisso até a morte), e assim começou uma investigação / acção colectiva que envolveu dezenas de colegas e suas famílias, resultando num processo judicial ainda em andamento : uma acção civil de grande importância para as centenas de pessoas envolvidas no processo bem como para o possível desenvolvimento do ambientalismo italiano. 


\section{Conclusões}

Os eventos do SMAL Lombardia e da Anic/Enichem de Manfredonia oferecem perspectivas diversas para a pesquisa histórica e etnográfica sobre o ambientalismo italiano em seus diferentes aspectos. Este artigo destina-se a ressaltar os elementos importantes de continuidade entre a época de 1970-78 de luta contra os efeitos nocivos e a nova temporada, que começou nos anos ' 90 , com o processo de Marghera. Esse processo abriu um novo capítulo na história das lutas contra a nocividade, um capítulo em que a acção do sindicato parecia ser substituída por (e as vezes estar em conflito com) a do indivíduo; porém, houve importantes elementos de continuidade com o período anterior de lutas. Se o Estatuto dos Trabalhadores parece hoje uma conquista distante sem qualquer potencial revolucionário acrescido, a cultura da medicina militante permanece viva, e o papel dos peritos / activistas (não só médicos, mas também engenheiros e advogados) na prestação de apoio às queixas dos trabalhadores manteve-se de fundamental importância na formação das investigações judiciais, tanto em Manfredonia como em Marghera. De grande interesse também aparece, em continuidade com os anos ' 70 , a contribuição feita pelo feminismo na organização do ambientalismo cidadão e da batalha pelo reconhecimento do dano. $O$ papel da subjectividade feminina e, claro, o aspecto de uma acção legal, aproxima a história de Manfredonia com a dos movimentos para a 'justiça ambiental' - uma forma de controlo da poluição, que nasceu em os EUA em meados dos anos 80, mas que se está espalhando globalmente [21]. A subjectividade da classe trabalhadora, organizada ou não, na luta para a 'justiça ambiental' é também um elemento comum a outros contextos geográficos e históricos - bem como suas contradições e dificuldades. Esse, no entanto, continua a ser o aspecto menos estudado do chamado "ambientalismo popular", apresentando-se assim como o aspecto em que futuras pesquisas podem dar os resultados mais interessantes.

\section{BIBLIOGRAFIA}

Adorno, S. e Neri Serneri, S. (Orgs). (2009)., Industria, ambiente e territorio. Per una storia ambientale delle aree industriali italiane. Bologna : Il Mulino

Allen, B. (2003). Uneasy Alchemy. Citizens and Experts in Louisiana's Chemical Corridor Disputes, Harvard: MIT Press: Harvard

Allen, B. (2007). La trasformazione industriale del basso corso del Mississippi in Louisiana, I Frutti di Demetra. Bollettino di Storia e Ambiente, 14, 47-56.

Armiero, M. (2009). Un altro ambientalismo è possibile. Anzi c'è già. In Joan Martinez Alier, Ecologia dei poveri (xi-xvii.). Milano : Jaca Book

Barca, S. (org) (2005). Massimo Menegozzo : Lavoro e salute in Italia. I Frutti di Demetra. Bollettino di Storia e Ambiente, 5, 63-70

Laboreal, Volume $6 \mathrm{~N}^{\circ} 2$ | 2010 
Berlinguer, G. (1991). Storia e Politica della Salute. Milano : Franco Angeli

Bettin, G. (org) (1998), Petrolkimico. Le voci e le storie di un crimine di pace. Milano : Baldini Castoldi Dalai

Calavita, K. (1986). Worker Safety, Law and Social Change: The Italian Case, Law \& Society Review 2, 189-228

Carnevale, F. e Baldasseroni, A. (1999). Mal da Lavoro : Storia della Salute dei Lavoratori. RomaBari : Laterza

Centemeri, L. (2006). Ritorno a Seveso. Il Danno Ambientale, il suo Riconoscimento, la sua Riparazione. Milano: Mondadori

CGIL-CISL-UIL Federazione Provinciale di Milano (1976). Salute e Ambiente di Lavoro. L'esperienza degli SMAL. Milano : Mazzotta.

Crepas, N. (1998). Industria. In Massimo Firpo, Nicola Tranfaglia e Pier Giorgio Zunino (Orgs), Guida all'Italia Contemporanea, 1861-1997 (287-422). Milano : Garzanti

De Luna, G. (2008) Le ragioni di un decennio. 1969-1979. Militanza, violenza, sconfitta, memoria. Milano : Feltrinelli

Dewey, S., (1998). Working for the environment. Organized Labor and the origins of Environmentalism in the United States, 1948-1970, Environmental History, 1, 45-63

Di Luzio, G. (2003). I Fantasmi dell'Enichem. Milano : Baldini Castoldi Dalai

Firpo, M. (2009). Eixos de desenvolvimento econômico e geração de conflitos socioambientais no Brasil : desafios para a sustentabilidade e a justiça ambiental, Ciência e Saúde Colectiva, 6, 1983-94.

Gordon, S., (1998). Shell No! OCAW and the Labor-Environmental Alliance, Environmental History, 4, 460-87

Graf von Hardenberg, W. e P. Pelizzari, (2008). The environmental question, employment and development in Italy's left, Left History 2, 77

Langiu, A. e Portaluri, M. (2008). Di Fabbrica si muore. San Cesario di Lecce : Manni

Luzzi, S. (2009). Il Virus del Benessere. Ambiente, Salute, Sviluppo nell'Italia Repubblicana. RomaBari : Laterza

Martínez Alier J. (2005), El Ecologismo de los Pobres. Conflictos Ambientales y Lenguajes de Valoración. Icaria : Barcelona.

Merchant, C. (2005). Radical Ecology. In Search for a Livable World. London : Routledge

Musso, S. (1998). Lavoro e occupazione. In Massimo Firpo, Nicola Tranfaglia e Pier Giorgio Zunino (Orgs), Guida all'Italia Contemporanea, 1861-1997 (485-544). Milano : Garzanti

Obach, B.K., (2004). Labor and the Environmental Movement. The Quest for Common Ground. Cambridge (MA): The MIT Press

Oddone, I. et al. (1977). Ambiente di lavoro. La fabbrica nel territorio. Roma : Edizioni Scientifiche Italiane

Parsons, H.L (org) (1977). Marx and Engels on Ecology. Westport and London: Greenwood Press

Signorelli, A., (1995). Movimenti di popolazione e trasformazioni culturali. In Storia dell'Italia repubblicana, vol. 4. La Trasformazione dell'Italia : Sviluppo e Squilibri (pp. 589-658).Torino : Einaudi 
Tomaiuolo, F. (2006). 1976-2006 : Trent'anni di arsenico all'Enichem di Manfredonia, I Frutti di Demetra. Bollettino di Storia e Ambiente, 12, 33-41.

Tonelli, P. (2006). Salute e lavoro. In Luigi Falossi (org), Il ‘900 : Alcune Istruzioni per l'Uso (pp. 45-65) Firenze : La Giuntina

Tonelli, P. (2007). La salute non si vende. Ambiente di lavoro e lotte di fabbrica tra anni '60 e '70. In Luigi Falossi and Francesco Loreto (orgs), I Due Bienni Rossi del ‘900. 1919-1920 e 1968-1969. Studi e Interpretazioni a Confronto (pp. 341-52). Roma : Ediesse

White, R., (1996). ‘Are You an Environmentalist, or Do You Work for a Living?' Work and Nature. In William Cronon (org) Uncommon Grounds. Rethinking the Human Place in Nature, (pp. 171-85). New York, W.W. Norton

\section{NOTAS}

1. Entrevista realizada pela autora: ver Barca (org) (2005). Uma visão diferente é manifestada, por exemplo, por um outro protagonista da mesma estação, Ivar Oddone (1977). Não há muitos estudos históricos sobre a relação entre movimento ambientalista e movimento sindical em Itália. As reconstruções disponíveis, no entanto, parecem acentuar a dificuldade dos relacionamentos, especialmente desde a recessão económica de 1977-78. Para uma revisão crítica sobre este assunto ver, por exemplo: Graf von Hardenberg e Pelizzari 2008.

2. Sobre a relação entre o movimento operário e o movimento ambiental nos EUA existe agora uma historiografia especializada: ver, por exemplo White (1995), Gordon (1998), Dewey (1998), Obach (2004). Na dialética entre os cidadãos e especialistas na área de risco industrial, consulte Allen $(2003,2007)$.

3. Esta visão encontra-se em Karl Marx, particularmente no Livro I do Capital, onde se abordam as condições de vida no sistema de fábrica em relação com a saúde pública, bem como em Engels, no seu famoso inquerito sobre as condições da classe trabalhadora inglesa: para uma selecção de textos dos dois autores sobre este assunto, ver Parsons (1977), pp. 185-205.

4. Sobre industria e migrações internas em Itália ver Signorelli (1995), Musso (1998), Crepas (1998). Sobre o impacto ambiental da industrialização ver Adorno e Serneri (2009) e Luzzi (2009).

5. Ver Carnevale e Baldasseroni (1999) 147-229; Calavita (1986); Berlinguer (1991).

6. Sobre o renovamento da hygiene industrial italiana nos anos '60 e '70, ver Carnevale e Baldasseroni (1999), 230-82; ver tambem Tonelli (2006, 2007). Sobre a mobilitação política juvenil dos anos '70 em Itália, ver De Luna (2008).

7. A expressão é relatada por Massimo Menegozzo: ver Barca (org) (2005), 67. Na mesma entrevista se sublinha a relaçao entre lutas contra a nocividade e reforma de saúde pública; o assunto encontra-se também em CGIL-CISL-UIL (1976) 189-99.

8. Esta renovação da medicina occupacional italiana nos anos ' 60 -'70 tornava-a num tipo de ciência que a filósofa Sandra Harding chama 'strong objectivity', isto é, um conhecimento construido de forma compartilhada entre especialistas/activistas e sujeitos sociais oprimidos pelo saber/poder dominante. Na "strong objectivity", a objectividade científica não è dada pela imparcialidade do sujeito que conhece, mas pela sua abilidade de reconhecer as relações de poder envolvidas no processo de conhecimento. Uma discussão das potencialidades da 'objectividade forte' no estudo dos riscos industriais, encontra-se em Allen (2003), pp. 6-7, 118, 140, 149.

9. No relato de Massimo Menegozzo, a individuaçao dos quatro fatores de risco foi feita por um grupo de sociólogos do trabalho da Universidade de Torino na segunda metade dos anos '60: ver Barca (org) (2005), 65; isto foi divulgado, a partir de 1969, por uma publicação sindical entitulada L'ambiente di lavoro, da autoria de Gastone Marri e Ivar Oddone. 
10. Ver CGIL-CISL-UIL (1976), 110.

11. No texto referido não aparecem nomes de mulheres, portanto podemos considerar que, pelo meno nesta fase, os funcionarios SMAL eram todos homens.

12. O relatorio respeitante a este caso encontra-se em CGIL-CISL-UIL (1976), pp. 74-85.

13. Ibid, 143-49.

14. Ibid, 189.

15. Para a historia do acidente de Manfredonia refiro-me sobretudo ao livro de Di Luzio (2003); também se pode ver Tomaiuolo (2006) e Luzzi (2009), pp. 152-55.

16. A informação encontra-se em Di Luzio (2003), p. 74. O autor cita um trecho da publicação "Ambiente e Saúde na Itália", em que a Organização Mundial da Saúde declarou desejável estabelecer um programa de vigilância epidemiológica na área de Manfredonia para monitorizar os efeitos do incidente de '76 a longa distância, dada a latência dos efeitos na saúde associados à exposição ao arsênico.

17. Sobre o impacto social do desastre de Seveso ver Centemeri (2006). Ver também Luzzi (2009), pp. $140-155$.

18. Sobre o ecofeminismo ver Merchant (2005), pp. 193-222.

19. $O$ encontro entre Portaluri e Lovecchio foi o objecto principal da entrevista realizada pela autora com Portaluri em Abril 2009. O encontro está também narrado em Langiu e Portaluri (2008).

20. Ver Bettin (org) (1998).

21. Sobre a justiça ambiental há uma ampla literatura em Inglés, embora algums estudos estejam agora disponíveis em Italiano, Espanhol e Português. Ver, por exemplo: Armiero (2009); Martinez Alier (2005); Firpo (2009).

\section{RESUMOS}

Este artigo oferece uma reflexão preliminar para a investigação histórica sobre um aspecto até hoje pouco considerado do ambientalismo italiano: o que vou chamar "ambientalismo do trabalho", isto é as lutas pela saúde nos ambientes de trabalho e de vida da classe trabalhadora. A história começa desde um encontro - entre uma geração de 'especialistas' em higiene industrial e uma outra de trabalhadores/as de fábrica - que teve lugar no coração do triângulo industrial italiano entre os anos ' 60 e ' 70 . Este encontro produziu novas formas de consciência ambiental e acção política, o que denominarei "ambientalismo do trabalho". Em seguida, a narração move-se para uma área de indústria petroquímica no Sul da Itália entre os anos '70 e ' 90 , onde as contradições da relação entre trabalho, saúde e meio ambiente explodiam e se reconfiguravam em diferentes formas. A minha intenção neste artigo é a de sugerir uma nova interpretação dessas lutas, inspirada por uma recente literatura histórico-ambiental sobre a nocividade industrial.

Este artículo presenta una reflexión preliminar para la realización de una investigación histórica sobre un aspecto del movimiento ecologista italiano que hasta hoy ha sido poco considerado y que denomino como "ambientalismo del trabajo", para refirme a las luchas por la salud en los ambientes de trabajo y en la vida de la clase trabajadora. Mi análisis parte del encuentro entre un grupo de 'especialistas' en higiene laboral y un grupo de obreros y obreras, que tuvo lugar en el corazón del triángulo industrial italiano entre los años 60 y los 70 . Este encuentro condujo a 
nuevas formas de conciencia ambiental y de acción política que designo como "ambientalismo del trabajo". A continuación, la narración se moverá hacia un área de la industria petroquímica al sur de Italia entre los años 70 y los 90, donde las contradicciones de la relación entre el trabajo, la salud y el medio ambiente, explotaban y remontaban de diferentes formas. Mi intención con el presente artículo es sugerir una nueva visión sobre estas luchas inspirada en la nueva literatura histórico-ambiental sobre la nocividad industrial.

Cet article présente une réflexion préliminaire à une recherche historique sur un aspect peu exploré à ce jour de l'environnementalisme italien. Il s'agit de ce que je définis comme “ environnementalisme du travail ", c'est à dire, les luttes pour la santé dans les environnements de travail et de vie, menées par la classe des travailleurs. L'histoire commence par une rencontre entre une génération d"' experts" en hygiène industrielle et une génération de travailleurs de l'industrie qui a eu lieu au cœur du " triangle industriel " italien entre les années 1960-1970. Cette rencontre a produit des formes nouvelles de conscience concernant l'environnement et l'action politique, ce que je nomme "environnementalisme du travail ". Ensuite, la narration se déplace dans une région de l'industrie pétrolochimique au Sud de l'Italie entre les années 1970-1990. Ici les contradictions des relations entre travail, santé et environnement ont explosé et ont assumé différentes formes. L'objectif de cet article est d'avancer une nouvelle interprétation de ces luttes, à partir d'une littérature historico-environnementale récente centrée sur la nocivité industrielle.

This article presents a preliminary reflection for conducting historical research on an item which has so far been little considered in the study of the Italian environmental movement: what I will call "labour environmentalism", that is the struggle for health in the work and living environment of the working class. The story told in this article starts with the meeting between a group of 'specialists' in occupational hygiene and a group of workers, which took place in the heart of the Italian industrial triangle between 1960 and 1970. This meeting led to new forms of environmental awareness and political action that I will designate as "labor environmentalism". Then the story moves to an area of petrochemical industry in southern Italy between the 1970s and the 1990s, where the contradictions of the relationship between work, health and the environment exploded and were reconfigured in different ways. My intention with this article is to suggest a new vision of these struggles, inspired by a recent historical literature about industrial hazard.

\section{ÍNDICE}

Mots-clés: environnementalisme du travail, luttes contre les nocivités, "Services de Médecine pour les Environnements de Travail ", industrie pétrolochimique, Manfredonia

Palabras claves: ambientalismo del trabajo, luchas contra la nocividad, "Servizi di Medicina per gli Ambienti di Lavoro", industria petroquímica, Manfredonia

Keywords: labour environmentalism, anti-toxic struggles, "Servizi di Medicina per gli Ambienti di Lavoro", petrochemicals, Manfredonia

Palavras-chave: ambientalismo do trabalho, lutas contra a nocividade, "Servizi di Medicina per gli Ambienti di Lavoro", industria petroquímica, Manfredonia 
AUTOR

STEFANIA BARCA

Centro de Estudos Sociais, Universidade de Coimbra sbarca@ces.uc.pt 